\title{
Pediatric Melanoma and Drug Development
}

\author{
Klaus Rose ${ }^{1, *}$ and Jane M. Grant-Kels ${ }^{2}$ \\ 1 klausrose Consulting, Pediatric Drug Development \& More, 4125 Riehen, Switzerland \\ 2 Department of Dermatology, University of Connecticut Health Center, Farmington, CT 06030, USA; \\ grant@uchc.edu \\ * Correspondence: klaus.rose@klausrose.net
}

Received: 19 February 2018; Accepted: 14 March 2018; Published: 20 March 2018

\begin{abstract}
Importance-Pediatric melanoma occurs, albeit rarely. Should patients be treated by today's medical standards, or be subjected to medically unnecessary clinical studies? Observations-We identified international, industry-sponsored pediatric melanoma studies triggered by regulatory demands in www.clinicaltrials.gov and further pediatric melanoma studies demanded by European Union pediatric investigation plans. We retrieved related regulatory documents from the internet. We analyzed these studies for rationale and medical beneficence on the basis of physiology, pediatric clinical pharmacology and rationale. Regulatory authorities define children by chronological age, not physiologically. Newborns' organs are immature but they develop and mature rapidly. Separate proof of efficacy in underage patients is justified formally/regulatorily but lacks medical sense. Children-especially post-puberty—and adults vis-a-vis medications are physiologically very similar. Two adolescent melanoma studies were terminated in 2016 because of waning recruitment, while five studies in pediatric melanoma and other solid tumors, triggered by European Union pediatric investigation plans, continue recruiting worldwide. Conclusions and Relevance-Regulatory-demanded pediatric melanoma studies are medically superfluous. Melanoma patients of all ages should be treated with effective combination treatment. Babies need special attention. Children need dose-finding and pharmacokinetic studies but adolescents metabolize and respond to drugs similarly to adults. Institutional Review Boards/ethics committees should suspend ongoing questionable pediatric melanoma studies and reject newly submitted questionable studies.
\end{abstract}

Keywords: pediatric drug development; Pediatric Investigation Plan (PIP); pediatric pharmaceutical legislation; EU pediatric regulation; pediatric clinical pharmacology; developmental pharmacology; pediatric laws; pediatric clinical studies

\section{Introduction}

Metastatic malignant melanoma, once incurable, can today be treated, even in some cases with durable responses [1]. Pediatric melanoma has three major challenges: (1) differentiation between conventional adult-type and other melanoma types [2]; (2) differentiation between melanoma simulants that are seen more often in children than in adults (spitz nevi) [2]; and (3) treating patients appropriately despite their age [3]. The Food and Drug Administration (FDA) and the European Medicines Agency (EMA) promote and require pediatric studies [4-6]. In melanoma, such studies appear to recruit predominantly patients with adult-type conventional melanoma [7]. A new definition of underage patients in the context of pharmaceutical treatment should be considered, together with a thorough revision of drug approval in the various pediatric age groups.

\section{Methods}

We identified terminated and ongoing international, industry-sponsored pediatric melanoma studies in www.clinicaltrials.gov, excluding studies that recruit(ed) both adolescents and adults to 
focus on truly pediatric studies. However, we included studies that recruited children, adolescents and young adults up to 30 years of age. We retrieved related EMA/FDA documents from the internet. We identified further pediatric melanoma studies demanded by the EMA in pediatric investigation plans (PIPs). We analyzed the regulatory rationale and medical beneficence of terminated, ongoing and demanded studies on the basis of physiology, pediatric clinical pharmacology and reason. PIP decisions and www.clinicaltrials.gov-listed studies can be internet-retrieved by their respective number.

\section{Background}

Pediatric melanoma is rare but is captured in registries [8-10] and is eagerly discussed [2,3,11-17]. The literature describes it in patients from $<10$ to $\leq 21$ years of age [3]. Should adolescents be therapeutically considered children? The American Academy of Pediatrics (AAP) defines children in the context of healthcare as $\leq 21$ years but accepts pediatric healthcare for older patients with special needs [18]. Although these age ranges are appropriate for hands-on pediatric clinical care, they should not be used to limit access to pharmacological treatment.

The claim that children are discriminated against evolved after US law, in 1962, established clinical trials as the basis for regulatory drug approval, a principle now recognized worldwide [19]. Also, jurisdiction over prescription drug advertising was transferred to the FDA [20]. In the 1950s, drug toxicities in newborns had been reported [21,22]. From 1962 onwards, drug developers included pediatric warnings on drug labels to avoid potential lawsuits. As a result, these drugs could not be advertised for children. Shirkey claimed this denied children the use of drugs and characterized children as "therapeutic orphans" [23]. The AAP claimed that drug prescription for children without explicit FDA certification was experimental [24] and that children needed separate pharmacological evaluation of new drugs for all age groups [25]. The AAP guideline of 1995 [25] explicitly referenced the toxicities reported in the 1950s [21,22]. FDA and AAP lobbying resulted in a 1997 law that rewarded pediatric studies with voluntary "pediatric exclusivity" of an additional six months' protection against generic competition [4]. When a company submits a proposal and the FDA agrees, it issues a "Written Request" (WR). After study report submission and FDA scrutiny, pediatric exclusivity is granted [4]. A second law authorized the FDA to mandate pediatric studies without reward [4]. Both laws are now permanent [26].

This inspired the European Union (EU) to establish its own pediatric regulation, in effect since 2007 [4,27]. Without a pediatric investigation plan (PIP), new drugs cannot get adult EU-approval, unless the targeted disease is PIP-exempted [4-6]. PIPs must address juvenile animal studies, formulations (e.g., tablets vs. syrup), pediatric studies and more. The EMA has until now issued $>1000$ PIPs [28].

The reported toxicities had been in premature newborns [21,22]. Also, further toxicities reported later under the sensational sub-headline "CONTINUED PEDIATRIC THERAPEUTIC DISASTERS" listed until the 1980s only toxicities in preterm newborns and newborns [29]. The AAP warnings were, in our opinion, inappropriately extended to all children by "extrapolating" toxicities from physiologically immature newborns to all children. Pediatric laws responded to the AAP's "moral imperative to formally study drugs in children so that they can enjoy equal access to existing as well as new therapeutic agents" [25]. Children were defined not based upon physiology but administratively: FDA $<16$ [30], EU < 18 years [4,6,27].

\section{Results}

In 2008, the EMA withdrew adolescent melanoma from the list of PIP-exempted diseases [5]. Thirteen melanoma PIPs were issued (Table 1). Twelve PIPs demand systemic monotherapy studies in melanoma or solid tumors including melanoma [5], this includes the original ipilimumab melanoma PIP [31]. The talimogene PIP demands local injection into melanoma and other non-central nervous system (CNS) malignant solid tumors. Two PIP decisions that originally demanded pediatric studies $[32,33]$ were later changed into waivers (no pediatric studies demanded). 
Table 1. European Medicines Agency (EMA) melanoma Pediatric Investigation Plans (PIPs).

\begin{tabular}{ll}
\hline Compound & PIP Number \\
\hline Binimetinib & EMEA-001454-PIP03-15 \\
Cobimetinib & EMEA-001425-PIP01-13-M01 \\
Dabrafenib & EMEA-001147-PIP01-11-M03 \\
Encorafenib & EMEA-001588-PIP01-13 \\
Ipilimumab * & EMEA-000117-PIP02-10 [31] • EMEA-000117-PIP02-10-M07 \\
MAGE-A3 recombinant protein ** & EMEA-001099-PIP02-11 [32] • EMEA-001099-PIP02-11-M01 \\
Nivolumab & EMEA-001407-PIP01-12 \\
Paclitaxel & EMEA-001308-PIP01-12 \\
Pembrolizumab & EMEA-001474-PIP01-13 \\
Selumetinib & EMEA-001585-PIP01-13 \\
Talimogene laherparapvec & EMEA-001251-PIP01-11-M03 \\
Trametinib & EMEA-001177-PIP01-11-M02 \\
Vemurafenib ** & EMEA-000978-PIP01-10 [33] • EMEA-000978-PIP01-10-M01 \\
\hline
\end{tabular}

* The first ipilimumab melanoma PIP, EMEA-000117-PIP02-10 is retrievable through the EMA document library [31]. Its current version M07 (7th modification) can be retrieved through Google. ${ }^{* *}$ PIPs later changed into waivers (no pediatric studies required). Original PIPs can be retrieved by the EMA document library, the respective link is referenced; current PIP versions can be googled by its respective number.

Melanoma PIPs require variably PK data in patients aged from 6 months to 17 years, 1-17, 12-17, $\leq 24$ and $\leq 30$ years; for ipilimumab, nivolumab, paclitaxel, pembrolizumab and trametinib they demand randomized comparisons [5]. Talimogene is an oncolytic for direct injection into unresectable melanoma tissue [34]. The talimogene PIP demands two studies on injection into melanoma tissue or other advanced non-CNS tumors in "pediatric" patients aged 2-17 years.

In 2008, the US National Cancer Institute (NCI) initiated the first pediatric ipilimumab study [35]. In 2011, the FDA approved ipilimumab for melanoma [36] and the EMA issued an ipilimumab melanoma PIP [31]. In 2014, the FDA issued an ipilimumab WR (see Table 2) [37]. The developer negotiated with both the EMA and the FDA and provided ipilimumab for the first pediatric NCI study [35]. EMA and FDA incorporated the NCI study into their pediatric demands (EMA)/written request (FDA). The NCI study was completed with 33 patients-including 12 melanoma patients-and was published [38]. The PIP/WR ipilimumab clinical study \#2 was initiated, listed on www. clinicaltrials.gov [39] and eventually reported [40].

Table 2. First two ipilimumab Written Requested (WR) clinical studies.

1. An open label, dose-escalation study of ipilimumab in pediatric patients (aged 1-21 years) with refractory cancers.

2. A clinical study of ipilimumab in pediatric patients $(12-<18$ years) with unresectable or metastatic melanoma to evaluate PK and safety.

- $\quad$ Efficacy in adolescent patients (12-<18 years) will be determined by extrapolation from results observed in adult patients treated with ipilimumab for unresectable or metastatic melanoma.

Two industry-sponsored international melanoma studies in adolescents were terminated in 2016 because recruitment had waned, predominantly due to now available combination treatment (Table 3) [41]. The ipilimumab study had been both WR/PIP-requested [5], the vemurafenib study PIP-demanded (Table 3) [42]. After the vemurafenib study was terminated, the EMA changed the vemurafenib PIP decision (Table 3) into a waiver, although the original decision had already triggered a clinical study [42].

Five industry-sponsored, PIP-demanded studies in children, adolescents and young adults with melanoma and other tumors are ongoing (Table 4). For studies' centers, see Table 5. 
Table 3. Terminated industry-sponsored international studies in adolescents with melanoma.

\begin{tabular}{|c|c|c|c|c|c|c|}
\hline Study \# & Abbreviated Study Description & Centers & Sponsor & Pts & Age (y) & PIP/WR \\
\hline NCT01519323 & $\begin{array}{l}\text { Vemurafenib in Stage IIIC/IV Melanoma } \\
\text { with BRAFV600 Mutations }\end{array}$ & 26 & Roche & 6 & $12-17$ & $\begin{array}{l}\text { EMEA-000978-PIP01-10 [34] } \\
\text { EMEA-000978-PIP01-10-M01 }\end{array}$ \\
\hline NCT01696045 & $\begin{array}{l}\text { Ipilimumab in untreated or previously } \\
\text { treated advanced or metastatic melanoma. }\end{array}$ & 32 & BMS & 12 & $12-17$ & $\begin{array}{l}\text { EMEA-000117-PIP02-10 (Original) [31] } \\
\text { EMEA-000117-PIP02-10-M07 (current) WR [37] }\end{array}$ \\
\hline
\end{tabular}

Abbreviations: Pts—patients; Roche-Hoffman-La Roche; BMS—Bristol-Myers Squibb; y-years.

Table 4. Ongoing industry-sponsored pediatric studies including patients with melanoma.

\begin{tabular}{|c|c|c|c|c|c|c|}
\hline Study \# & Abbreviated Study Description & Centers & Age & Pts & Sponsor & PIP \# \\
\hline NCT02332668 & $\begin{array}{l}\text { Pembrulizumab in advanced melanoma or } \\
\text { advanced R/R PDL1-positive solid tumors } \\
\text { or lymphoma }\end{array}$ & 45 & 6-month-17 y & 310 & MSD & EMEA-001474-PIP01-13 \\
\hline NCT01677741 & $\begin{array}{l}\text { Dabrafenib in advanced BRAF V600 } \\
\text { mutation-positive solid tumors }\end{array}$ & 27 & $1-17 y$ & 86 & GSK & EMEA-001147-PIP01-11-M03 \\
\hline NCT01962103 & Paclitaxel DF \& PE in R/R solid tumors & 20 & $\begin{array}{l}\text { 6-month-17 y Ph1 } \\
2-24 \text { y Ph2 }\end{array}$ & 107 & Celgene & EMEA-001308-PIP01-12 \\
\hline EUdraCT 2014-004685-25 & $\begin{array}{l}\text { Cobimetinib DE, S \& PK in previously } \\
\text { treated solid tumors }\end{array}$ & 41 & $\begin{array}{l}1-17 \text { y (DES) } \\
6-30 \text { y (ES) }\end{array}$ & 50 & Roche & EMEA-001425-PIP01-13-M01 \\
\hline NCT02756845 & $\begin{array}{l}\text { S\&E of talimogene laherparepvec in } \\
\text { melanoma and advanced non-CNS tumors }\end{array}$ & 17 & $\begin{array}{l}12-21 \text { y } \mathrm{Ph} 1 \\
2-11 \text { y } \mathrm{Ph} 2\end{array}$ & 18 & Amgen & EMEA-001251-PIP01-11-M03 \\
\hline
\end{tabular}

Abbreviations in alphabetic order: CNS—central nervous system; DE—dose escalation; DES—dose escalation study; DF—dose finding; ES—expansion study; GSK—GlaxoSmithKline; MSD-Merck, Sharp \& Dome; PE—preliminary; Ph1—phase 1; Ph2—-phase 2; PK—pharmacokinetics efficacy; Pts-Patients; Roche-Hoffman-La Roche; R/R—recurrent or refractory; S-safety; y-years. 
Table 5. Study centers of terminated and ongoing "pediatric" melanoma studies.

\begin{tabular}{|c|c|c|}
\hline Study \# & Compound & Study Centers \\
\hline NCT01519323 & Vemurafenib & $\begin{array}{l}\text { US: Los Angeles (CA), Aurora (CO), St. Peterburgh (FL), Bethesda (MD), Boston (MA), New York (NY), } \\
\text { Memphis (TN), Houston (TX) • Australia: Westmead, Brisbane } \bullet \text { France: Marseille, Pierre Benite } \bullet \text { Germany: Kiel, } \\
\text { Mainz, Tuebingen } \bullet \text { Israel: Jerusalem, Petach-Tikva } \bullet \text { Italy: Roma, Genova, Milano } \bullet \text { Poland: Wroclaw } \bullet \text { Slovakia: } \\
\text { Bratislava } \bullet \text { Spain: Esplugues De Llobregat-Barceona, Sevilla } \bullet \text { UK: Newcastle, Sutton }\end{array}$ \\
\hline NCT01696045 & Ipilimumab & $\begin{array}{l}\text { US: Phoenix (AZ), Los Angeles (CA), Orange (CA), Aurora (CO), Tampa (FL), Indianapolis (IN), Boston (MA), } \\
\text { Rochester (MN), New York (NY), Pittsburg (PA), Memphis (TN), Houston (TX), } 2 \times \text { Salt Lake City (UT) • Belgium: } \\
\text { Gent } \bullet \text { Denmark: Copenhagen } \bullet \text { France: Lyon, Marseille, Nantes, Villejuif Cedex } \bullet \text { Germany: Dortmund, Erlangen, } \\
\text { Hamburg, } 2 \times \text { Muenster } \bullet \text { Mexico: } 2 \times \text { Mexico DF, Leon } \bullet \text { Spain: Esplugues de Llobregat-Barcelona } \bullet \text { UK: Bristol, } \\
\text { Newcastle, Sutton }\end{array}$ \\
\hline NCT02332668 & Pembrulizumab & $\begin{array}{l}\text { US: Phoenix (AZ), Loma Linda (CA), } 2 \times \text { Los Angeles (CA), Madera (CA), Orange (CA), San Diego (CA), } \\
\text { San Francisco (CA), Aurora (CO), New Haven (CT), Washington DC, Atlanta (GA), Indianapolis (IN), } \\
\text { Iowa City (IA), Boston (MA), Ann Arbor (MI), } 2 \times \text { Minneapolis (MN), Cansas City (MO), Sant Louis (MO), } \\
\text { New York (NY), Cincinatti (OH), Cleveland (OH), Columbus (OH), Philadelphia (PA), Pittsburg (PA), } \\
\text { Memphis (TN), Nashville (TN), Dallas (TX), Fort Worth (TX), Houston (TX), Salt Lake City (UT), Seattle (WA), } \\
\text { Milwaukee (WI) • Australia: North Ride • Brazil: Sao Paulo } \bullet \text { Canada: Kirkland • France: Paris } \bullet \text { Germany: Haar } \\
\bullet \text { Israel: Hod Hasharon } \bullet \text { Italy: Rome } \bullet \text { Korea: Seoul } \bullet \text { New Zealnd: Wellinton } \bullet \text { Sweden: Stockholm } \bullet \\
\text { UK: Hoddesdon }\end{array}$ \\
\hline NCT01677741 & Dabrafenib & $\begin{array}{l}\text { US: Phoenix (AZ), Orange (CA), Baltimore (MD), Boston (MA), New York (NY), Cincinatti (OH), Memphis (TN), } \\
\text { Seattle (WA) • Australia: Parville, Subiaco } \bullet \text { Canada: Toronto } \bullet \text { Denmark: Copenhagen } \bullet \text { France: Marseille, } \\
\text { Paris cedex 05, Paris cedex 12, Toulouse, Villejuif cedex } \bullet \text { Germany: Heidelberg, Regensburg, Berlin } \bullet \text { Israel: } \\
\text { Jerusalem, Ramat-Gan } \bullet \text { Italy: Milano } \bullet \text { Spain: Esplugues de Llobregat-Barcelona, Madrid } \bullet \text { UK: Sutton, London }\end{array}$ \\
\hline NCT01962103 & Paclitaxel & $\begin{array}{l}\text { US: Phoenix (AZ), New York (NY) • Canada: Ontario } \bullet \text { France: Lyon, Nancy, Paris, Villejuif } \bullet \text { Italy: Firenze, } \\
\text { Genova, Milano, Padvoa, Rome, Torino } \bullet \text { Spain: } 2 \times \text { Barcelona, Madrid, Sevilla, Valencia } \bullet \text { Switzerland: Zuerich } \bullet \\
\text { UK: Sutton }\end{array}$ \\
\hline $\begin{array}{c}\text { EUdraCT } \\
\text { 2014-004685-25 * }\end{array}$ & Cobimetinib & Netherlands • Ireland $\bullet$ Denmark $\bullet$ UK $\bullet$ Germany $\bullet$ Spain \\
\hline NCT02756845 & Talimogene laherparepvec & $\begin{array}{l}\text { US: Wilmington (DE), Chicago (IL), Indianapolis (IN), Detroit (MI), NY (NY), Cincinatti (OH), Columbus (OH) } \bullet \\
\text { Canada: Montreal • France: Lyon, Marseille, Paris • Spain: Barcelona, Esplugues de Llobregat, Valenica, Madrid • } \\
\text { Switzerland: Basel, Zuerich }\end{array}$ \\
\hline
\end{tabular}

Explanations: Abbreviations for US states by two-letter codes of the US Postal Service. * www.clinicaltrialsregister.eu (EUdraCT) only lists countries, not individual study centers 


\section{Discussion}

Industry-sponsored pediatric melanoma studies are driven by the FDA/EMA in the spirit of the "therapeutic orphans" concept. These studies are regulatorily justified on the assumption of two distinct populations, adult versus pediatric, each requiring separate studies. Both US and EU laws claim concern for child health but closer inspection of key documents shows a regulatory rationale. For the FDA, a good example is the shift of wording from the FDA's first pediatric report to congress in 2001 to the second one in 2016. In 2001, it described expected clinical outcomes: "quicker recoveries from childhood illnesses, with fewer attendant hospital stays, physician visits and parental work days lost" [43]. In 2016, it reported "significant progress in terms of the number, timeliness and successful completion of studies of drugs in pediatric populations" [44]. This a shift away from clinical concerns towards a regulatory justification of pediatric studies. Also, the EMA wording suggests clinical concern, for example, their brochure entitled "Better Medicines for Children" [45]. However, the focus in this brochure is the authorization of drugs, not clinical care. The EMA 10-year report on EU pediatric regulation [46] in comparison to its recent publication by EMA employees [47] demonstrates their true motivation.

We find it questionable that the EMA required pediatric clinical studies in the first vemurafenib melanoma PIP [33] but thereafter changed the PIP decision into a full waiver (no pediatric studies required, Table 3), without a public explanation for why it had first required the developing company to initiate a study [42] and then waived this decision. Additionally, there are several clinical studies listed in www.clinicaltrials.gov for talimogene laherparepvec for various cancer types. If one of them should show statistically significant superiority, Amgen would ask for approval for a new indication. However, there is no medical merit in requiring Amgen to recruit 18 young patients to participate in an international clinical study with 17 centers (see Tables 4 and 5) for various non-central nervous system tumor types, including melanoma. All these patients have in common is that they are young (Table 4). These 18 patients are being studied because of a regulatory authority enforcing pediatric studies. Meanwhile these patients are not being advantaged of the newer combination therapies that are available.

Children and adolescents with adult-type conventional melanomas [2] should be treated with proven medications that are dose-adjusted for their weight and physiology. In preterm newborns, newborns and babies, absorption, distribution and excretion (ADME) are quite different. After roughly the first year of life, ADME becomes comparable to adults [48]. Children need PKand dose-finding studies, not separate proof of efficacy. Adolescents have mature bodies as far as pharmaceutical treatment is concerned. Patients of all ages deserve treatment with effective anti-melanoma combinations. This holds true even for the very rare cases of melanoma in babies and newborns, provided conventional melanoma is sufficiently differentiated from other melanoma types [2]. Institutional Review Boards (IRBs)/ethics committees (ECs) should not have approved the terminated studies (Table 3). The "pediatric" phase 1 ipilimumab study in children, adolescents and young adults [35,38] continued even after ipilimumab approval. After ipilimumab approval in 2011 this was no longer experimental, no longer a phase 1 study and had not been a pediatric study from the beginning.

Within pediatric academic clinical oncology, an international industry has evolved that is dedicated to FDA/EMA-promoted "pediatric" studies, as reflected in the number of study centers and planned patients in Tables 3-5. Not all clinical researchers involved in international pediatric melanoma studies are aware of the regulatory background. Participation in international studies offers prestige, networking, investigators' meetings, opportunities to publish and more. Certainly, the flow of funds is welcome. These funds are channeled by regulatory decisions. The regulatory authorities have been given much credit in promoting pediatric research but the studies we discuss here are to a large degree not pediatric studies and are without clinical beneficence. The conflicts of interest of regulatory authorities and pediatric researchers have so far been barely addressed in the scientific literature. It is time for medicine and academia to address this blind spot. 


\section{Conclusions}

IRBs/ECs should immediately suspend, worldwide, questionable monotherapy melanoma studies and reject newly submitted unnecessary pediatric studies. Melanoma patients from suspended studies should be offered combination treatment; other patients should be offered appropriate therapy, not monotherapy based on questionable regulatory requirements for pediatric studies. IRBs/ECs should uphold the Belmont report's principle of beneficence [49].

Conflicts of Interest: Klaus Rose has worked 20 years in pharmaceutical industry in clinical development and medical affairs. Independent since 2011, he consults on pediatric drug development, teaches, organizes conferences, edits books, and publishes. He receives annual royalties for a co-edited book on pediatric formulations. He still owns shares of his former employers Roche/Genentech and Novartis. His clients are pharmaceutical companies and academic institutions. He is also the father of a daughter with a rare syndrome and is biased against empty governmental promises. Jane Grant-Kels declares no competing interests.

\section{References}

1. Lejeune, F.J. The conquest of melanoma by immunotherapy. Melanoma Res. 2015, 25, 373-375. [CrossRef] [PubMed]

2. Pappo, A.S. Pediatric Melanoma: The Whole (Genome) Story. Am. Soc. Clin. Oncol. Educ. Book 2014, e432-e435. [CrossRef] [PubMed]

3. Wood, B.A. Paediatric Melanoma. Pathology 2016, 48, 155-165. [CrossRef] [PubMed]

4. Hirschfeld, S.; Saint-Raymond, A. Pediatric Regulatory Initiatives. Handb. Exp. Pharmacol. 2011, 205, 245-268. [PubMed]

5. Rose, K.; Walson, P.D. Do the European Medicines Agency (EMA) decisions hurt pediatric melanoma patients? Clin. Ther. 2017, 39, 253-265. [CrossRef] [PubMed]

6. Rose, K.; Walson, P.D. Do Pediatric Investigation Plans (PIPs) advance pediatric healthcare? Pediatr. Drugs 2017, 19, 515-522. [CrossRef] [PubMed]

7. Rose, K.; Grant-Kels, J. Most adolescents' melanomas are conventional malignant adult-type melanomas. Eur. J. Cancer 2018, in press. [CrossRef] [PubMed]

8. Wong, J.R.; Harris, J.K.; Rodriguez-Galindo, C.; Johnson, K.J. Incidence of childhood and adolescent melanoma in the United States: 1973-2009. Paediatrics 2013, 131, 846-857. [CrossRef] [PubMed]

9. Brecht, I.B.; Garbe, C.; Gefeller, O.; Pfahlberg, A.; Bauer, J.; Eigentler, T.K.; Offenmueller, S.; Schneider, D.T.; Leiter, U. 443 paediatric cases of malignant melanoma registered with the German Central Malignant Melanoma Registry between 1983 and 2011. Eur. J. Cancer 2015, 51, 861-868. [CrossRef] [PubMed]

10. Eggen, C.A.M.; Durgaram, V.V.L.; van Doorn, R.; Mooi, W.J.; Pardo, L.M.; Pasmans, S.G.M.A.; Hollestein, L.M. Incidence and relative survival of melanoma in children and adolescents in the Netherlands, 1989-2013. J. Eur. Acad. Dermatol. Venereol. 2017. [CrossRef] [PubMed]

11. Abboud, J.; Stein, M.; Ramien, M.; Malic, C. The diagnosis and management of the Spitz nevus in the pediatric population: A systematic review and meta-analysis protocol. Syst. Rev. 2017, 6, 81. [CrossRef] [PubMed]

12. LaChance, A.; Shahriari, M.; Kerr, P.E.; Grant-Kels, J.M. Melanoma: Kids are not just little people. Clin. Dermatol. 2016, 34, 742-748. [CrossRef] [PubMed]

13. Offenmueller, S.; Leiter, U.; Bernbeck, B.; Garbe, C.; Eigentler, T.; Borkhardt, A.; Classen, C.F.; Corbacioglu, S.; Dirksen, U.; Ebetsberger-Dachs, G.; et al. Clinical characteristics and outcome of 60 pediatric patients with malignant melanoma registered with the German Pediatric Rare Tumor Registry (STEP). Klin. Padiatr. 2017, 229, 322-328. [CrossRef] [PubMed]

14. Carrera, C.; Scope, A.; Dusza, S.W.; Argenziano, G.; Nazzaro, G.; Phan, A.; Tromme, I.; Rubegni, P.; Malvehy, J.; Puig, S.; et al. Clinical and dermoscopic characterization of pediatric and adolescent melanomas: Multicenter study of 52 cases. J. Am. Acad. Dermatol. 2018, 78, 278-288. [CrossRef] [PubMed]

15. Tracy, E.T.; Aldrink, J.H. Pediatric melanoma. Semin. Pediatr. Surg. 2016, 25, 290-298. [CrossRef] [PubMed]

16. Stefanaki, C.; Chardalias, L.; Soura, E.; Katsarou, A.; Stratigos, A. Pediatric Melanoma. J. Eur. Acad. Dermatol. Venereol. 2017, 31, 1604-1615. [CrossRef] [PubMed] 
17. Lu, C.; Zhang, J.; Nagahawatte, P.; Easton, J.; Lee, S.; Liu, Z.; Ding, L.; Wyczalkowski, M.A.; Valentine, M.; Navid, F.; et al. The Genomic Landscape of Childhood and Adolescent Melanoma. J. Investig. Dermatol. 2015, 135, 816-823. [CrossRef] [PubMed]

18. Hardin, A.P.; Hackell, J.M.; Committee on Practice and Ambulatory Medicine. Age Limit of Pediatrics. Pediatrics 2017, 140, e20172151. [CrossRef] [PubMed]

19. Rägo, L.; Santo, B. Drug Regulation: History, Present and Future. In Drug Benefits and Risks: International Textbook of Clinical Pharmacology, 2nd ed.; van Boxtel, C.J., Santo, B., Edwards, I.R., Eds.; IOS Press \& Uppsala Monitoring Centre: Uppsala, Sweden, 2008; Chapter 6; pp. 65-77.

20. Donohue, J. A History of Drug Advertising: The Evolving Roles of Consumers and Consumer Protection. Milbank Q. 2006, 84, 659-699. [CrossRef] [PubMed]

21. Burns, L.E.; Hodgman, J.E.; Cass, A.B. Fatal circulatory collapse in premature infants receiving chloramphenicol. N. Engl. J. Med. 1959, 261, 1318-1321. [CrossRef] [PubMed]

22. Silverman, W.A.; Andersen, D.H.; Blanc, W.A.; Crozier, D.N. A difference in mortality rate and incidence of kernicterus among premature infants allotted to two prophylactic antibacterial regimens. Pediatrics 1956, 18, 614-625.

23. Shirkey, H. Therapeutic Orphans. J. Pediatr. 1968, 72, 119-120, reprinted in Pediatrics 1999, 104, $583-584$. [CrossRef]

24. American Academy of Pediatrics (AAP). Committee on Drugs. Guidelines for the Ethical Conduct of Studies to Evaluate Drugs in Pediatric Populations. Pediatrics 1977, 60, 91-101.

25. American Academy of Pediatrics. Guidelines for the Ethical Conduct of Studies to Evaluate Drugs in Pediatric Populations, Committee on Drugs. Pediatrics 1995, 95, 286-294.

26. Food and Drug Administration Safety and Innovation Act (FDASIA). 2012. Available online: https://www. congress.gov/112/plaws/publ144/PLAW-112publ144.pdf (accessed on 16 March 2018).

27. Regulation (EC) No 1901/2006 of the European Parliament and of the Council of 12 December 2006 on Medicinal Products for Paediatric Use and Amending Regulation (EEC) No 1768/92, Directive 2001/20/EC, Directive 2001/83/EC and Regulation (EC) No 726/2004. Available online: http:/ / ec.europa.eu/health/ files/eudralex/vol-1/reg_2006_1901/reg_2006_1901_en.pdf (accessed on 16 March 2018).

28. EU Commission Report 2017: State of Paediatric Medicines in the EU-10 years of the EU Paediatric Regulation. Available online: https:/ / ec.europa.eu/health/sites/health/files/files/paediatrics/docs/2017_ childrensmedicines_report_en.pdf (accessed on 16 March 2018).

29. Christensen, M.L.; Helms, R.A.; Chesney, R.W. Is pediatric labeling really necessary? Pediatrics 1999, 104 (Suppl. 3), 593-597. [PubMed]

30. Hirschfeld, S. History of Pediatric Labeling. Available online: https:/ $/$ www.google.ch/url? sa =t\&rct=j\&q=\&esrc= s\&source=web\&cd=1\&cad=rja\&uact=8\&ved=0ahUKEwjn2YXDr5HYAhUDUBQKHe81DYcQFggzMAA\& url=https \%3A\%2F\%2Fwww.fda.gov\%2Fohrms\%2Fdockets\%2Fac\%2F03\%2Fslides\%2F3927S1_01_Hirshfeld\% 2520.ppt\&usg=AOvVaw2uP6W-YOVM7YYk0cq44bm8 (accessed on 16 March 2018).

31. EMEA-000117-PIP02-10. Available online: http://www.ema.europa.eu/docs/en_GB/document_library / PIP_decision/WC500108733.pdf (accessed on 16 March 2018).

32. Original MAGE-A3 Recombinant Protein PIP Decision EMEA-001099-PIP02-11. Available online: http:/ / www. ema.europa.eu/docs/en_GB/document_library/PIP_decision/WC500131210.pdf (accessed on 16 March 2018).

33. Vemurafenib PIP. 2011. Available online: http://www.ema.europa.eu/docs/en_GB/document_library/ PIP_decision/WC500106279.pdf (accessed on 16 March 2018).

34. Fountzilas, C.; Patel, S.; Mahalingam, D. Review: Oncolytic virotherapy, updates and future directions. Oncotarget 2017, 8, 102617-102639. [CrossRef] [PubMed]

35. Phase, I Study of Ipilimumab (Anti-CTLA-4) in Children and Adolescents with Treatment-Resistant Cancer. Available online: https: / clinicaltrials.gov/ct2/show / NCT01445379 (accessed on 16 March 2018).

36. Ipilimumab Prescribing Information. Available online: https://www.accessdata.fda.gov/drugsatfda_docs / label/2015/125377s073lbl.pdf (accessed on 16 March 2018).

37. Ipilimumab Written Request 2014. Available online: https://www.fda.gov/downloads/Drugs/ DevelopmentApprovalProcess/DevelopmentResources/UCM571258.pdf (accessed on 16 March 2018).

38. Merchant, M.; Wright, M.; Baird, K.; Wexler, L.; Rodriguez-Galindo, C.; Bernstein, D.; Delbrook, C.; Lodish, M.; Bishop, R.; Wolchok, J.D.; et al. Phase 1 trial of Ipilumamb in Ipilimumab in ped patients with advanced solid tumors. Clin. Cancer Res. 2016, 22, 1364-1370. [CrossRef] [PubMed] 
39. Phase 2 Study of Ipilimumab in Children and Adolescents (12 to < 18 Years) with Previously Treated or Untreated, Unresectable Stage III or Stage IV Malignant Melanoma. Available online: https:/ / clinicaltrials. gov/ct2/show / NCT01696045 (accessed on 16 March 2018).

40. Geoerger, B.; Bergeron, C.; Gore, L.; Sender, L.; Dunkel, I.J.; Herzog, C.; Brochez, L.; Cruz, O.; Nysom, K.; Berghorn, E.; et al. Phase II study of ipilimumab in adolescents with unresectable stage III or IV malignant melanoma. Eur. J. Cancer 2017, 86, 358-363. [CrossRef] [PubMed]

41. FDA Ipilimumab Clinical Review 125377/Supplement 87. Available online: https://www.fda.gov/ downloads/Drugs/DevelopmentApprovalProcess/DevelopmentResources/UCM572924.pdf (accessed on 16 March 2018).

42. BRIM-P: A Study of Vemurafenib in Pediatric Patients with Stage IIIC or Stage IV Melanoma Harboring BRAFV600 Mutations. Available online: https://www.clinicaltrials.gov/ct2/show /NCT01519323 (accessed on 16 March 2018).

43. The Pediatric Exclusivity Provision; January 2001. Status Report to Congress. Available online: https://www.fda. gov/downloads/Drugs/DevelopmentApprovalProcess/DevelopmentResources/UCM049915.pdf (accessed on 16 March 2018).

44. Best Pharmaceuticals for Children Act and Pediatric Research Equity Act. July 2016; Status Report to Congress; Department of Health and Human Services; Food and Drug Administration. Available online: https://www.fda.gov/downloads/ScienceResearch/SpecialTopics/PediatricTherapeuticsResearch/ UCM509815.pdf (accessed on 16 March 2018).

45. European Medicines Agency. Better Medicines for Children. Available online: http://www.ema.europa.eu/ docs/en_GB/document_library/Leaflet/2009/12/WC500026493.pdf (accessed on 16 March 2018).

46. European Medicines Agency. 10-Year Report to the European Commission. General Report on the Experience Acquired as a Result of the Application of the Paediatric Regulation. Available online: https: / / ec.europa.eu/health/sites/health/files/files/paediatrics/2016_pc_report_2017/ema_10_year_ report_for_consultation.pdf (accessed on 16 March 2018).

47. Tomasi, P.A.; Egger, G.F.; Pallidis, C.; Saint-Raymond, A. Enabling Development of Paediatric Medicines in Europe: 10 Years of the EU Paediatric Regulation. Pediatr. Drugs 2017, 19, 501-513. [CrossRef] [PubMed]

48. Kearns, G.L.; Abdel-Rahman, S.M.; Alander, S.W.; Blowey, D.L.; Leeder, J.S.; Kauffman, R.E. Developmental pharmacology—Drug disposition, action and therapy in infants and children. N. Engl. J. Med. 2003, 349, 1157-1167. [CrossRef] [PubMed]

49. The Belmont Report. Ethical Principles and Guidelines for the Protection of Human Subjects of Research. The National Commission for the Protection of Human Subjects of Biomedical and Behavioral Research April 18, 1979. Available online: https://www.fda.gov/ohrms/dockets/ac/05/briefing/2005-4178b_09_02_ Belmont\%20Report.pdf (accessed on 16 March 2018). 